\title{
Configuring A Mini-Laboratory and Desktop 3-Axis Parallel Kinematic Milling Machine
}

\author{
Sasa Zivanovic* - Milos Glavonjic - Dragan Milutinovic \\ University of Belgrade, Faculty of Mechanical Engineering, Serbia
}

Configuring new machine tools is a complex task that involves the use of a large range of conceptions, methods, models, virtual prototypes and simulations. This paper presents a methodology for configuring a new machine tool to the level of a virtual prototype by using CAD configurator Pro/WEB.Link and a top-down approach. This methodology is explained via an example of the development of a mini-laboratory and desktop 3-axis parallel kinematic milling machine (PKMM). The results are two variants of the virtual prototype and one real world prototype. The configured virtual prototypes are used for the verification of the machining program and programming system using machining simulation in the CAD/CAM environment. The mini-laboratory and desktop 3-axis PKMM has been verified by the successful machining of test workpieces. Keywords: CAD configurator, Pro/Web.Link, top-down, CAD/CAM, configuring, machine tool, machining simulation

Highlights

- $\quad$ CAD configurators with web interface and Top Down approach.

- $\quad$ Configuring and developing the new mini-laboratory and desktop 3-axis PKMM.

- Machining simulation in the CAD/CAM system.

- Virtual machine is included in the control and programming system.

- Mini-laboratory and desktop 3-axis PKMM was verified by simulation and by the machining of standardized test pieces.

\section{O INTRODUCTION}

Globalization and the shortening of products' life cycles have caused dramatic changes in the configuring and designing of new products. The customization of products has become a trend in recent years [1] to [3]. Consequently, the customization of configuring process represents a critical issue that can be addressed by adapting interfaces to $\mathrm{CAD} / \mathrm{CAM}$ systems, thereby using the web interface to rapidly configure a new product.

The application of the web interface as a link to the CAD system is currently widely used in the development of various products [4] to [6]. Examples of some of the available CAD configurators of standard components from different manufacturers are shown in Fig. 1. Available CAD configurators can provide standard, but not custom-made components, which are also required for the process of designing the product families. Programming customized configurators for a family of particular components is possible using programmable web interfaces, such as Pro/Web.Link in the Creo CAD/CAM system. This approach is applicable at the component and assembly levels.

The conceptual design of product families has inspired many research efforts [7] to [9]. The stateof-the-art methods can be classified into two main categories: scalable and configurational product family design [10].

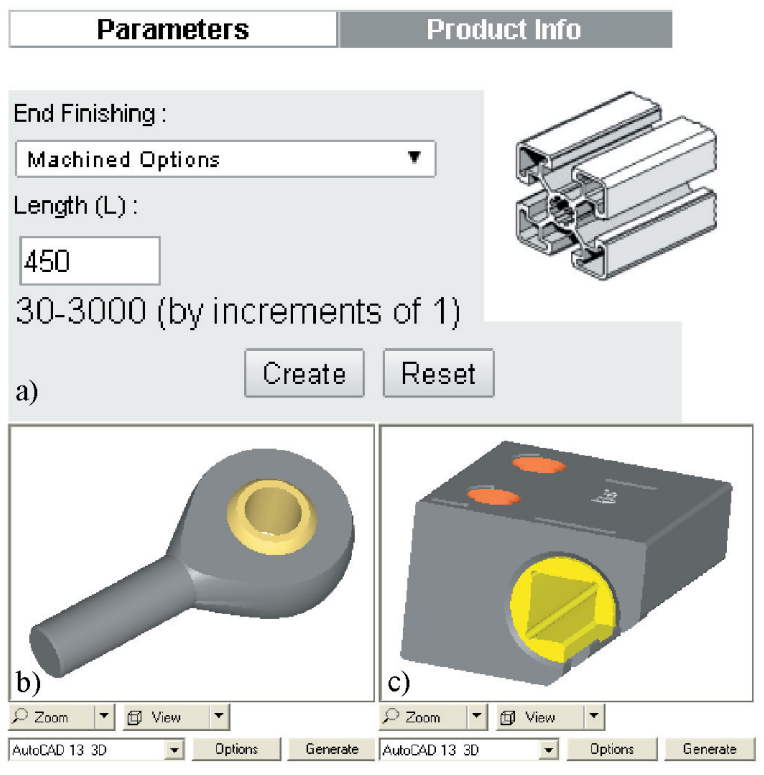

Fig. 1. The choice of standard components in CAD configurator

[4] and [6]

Scalable product family design refers to the definition of scaling variables (parameters) that are used to scale product components/subassemblies in one or more directions in order to address a variety of customer requests [10] and [11]. The second approach is configurational product family design (also known as module-based product family design) in which the family members are configured by adding, removing 
or substituting one or more functional modules from the initially developed modular product [12]. The application of programmable web interfaces in the design of a product family is an emerging field of research.

In [6] the authors use Pro/Web.Link and Pro/ Engineer $\mathrm{CAD} / \mathrm{CAM}$ system for designing a family of trailers. A similar approach presented in [8] investigates configuring a family of products starting from a low-level skeleton model. A lamp and a golf cart were the examples considered.

In this paper, the application of CAD configurators with web interfaces in configuring the components and assemblies of new machine tools are investigated. Compared to the examples presented in [7] and [8], a machine tool is a highly complex product in which the kinematics of the machine is a critical issue. Therefore, the conceptual (skeleton) model of a machine tool should incorporate all the kinematic joints that will enable the kinematic verification of the mechanism.

The main benefits of the web interface application for configuring new machine tools can be expressed as follows:

- Interactive decision-making that is based on the configuration of the machine tool and its settings according to the specific input data based on user requirements, database access, standards, recommendations, functional requirements, etc.;

- Automation of machine tool modelling and configuration, with new input parameters that can be interactively set;

- Use of a large number of standard components and generation of machine configuration that can be easily remodelled;

- Use of CAD configurators with the web interface for unique components;

- Verification of the machine virtual prototypes through simulation of mechanism kinematics during machining according to a control program (this is enabled by incorporation of all kinematic joints into the machine conceptual model);

- Improved efficiency for machine designers, in order to reduce the time required to configure the new product.

Finished solid models of the standard components with the desired dimensions, based on a query filled in by the user, can be downloaded. Downloaded standard components should not be further developed at all, and they are directly built in the main assembly. This approach is applicable in configuring new machine tools [13]. In this paper, the web configurators, web interface, $\mathrm{CAD} / \mathrm{CAM}$ systems and Pro/Web.Link are utilized for the development of a mini-laboratory and a desktop 3-axis parallel kinematic milling machine (PKMM).

PKMM is a research-and-development topic in many laboratories [14] and [15], although many of them, unfortunately, in fact, do not have a PKMM. Therefore, the use of a mini-laboratory and desktop educational 3-axis PKMM has been suggested as an aid in the process of acquiring basic experience with a PKMM [16] to [18]. Research works that consider diverse aspects of PKMM have been published [19] and [20].

The simulation of the machining process created in this paper includes the simulation of machine operation based on a generated program in a $\mathrm{CAD} /$ CAM system. However, since the mini-laboratory machine is used for the machining of workpieces of soft materials (Styrofoam), the simulation does not include finite element (FE) analysis of cutting forces, as in [21] and [22].

The rest of the paper is organized as follows. In Section 1, a general methodology for application of CAD configurators, Pro/WEB.Link and top-down approach in configuring new products is presented. This methodology was applied for designing minilaboratory and desktop 3-axis PKMM in Section 2. We have developed two virtual prototypes, one of which was implemented in the real world. In Section 3 , the configured virtual prototypes are used for the verification of the machining program and off-line programming system using machining simulation in the $\mathrm{CAD} / \mathrm{CAM}$ environment, which was possible because the skeleton model of the virtual prototypes had the incorporated all kinematic joints. During the simulation, PKMM tool paths were based on programs that were created using CAM systems [23]. In Section 4 , the test workpieces that were used for verifying the control and programming system on a real world laboratory prototype are presented.

\section{CONFIGURING BY PRO/WEB.LINK AND TOP-DOWN APPROACH}

Pro/Web.Link links the internet to Creo Parametric, enabling the use of web as a tool to automate and streamline parts of the engineering process [24] and [25]. This paper describes the implementation of a simple automation solutions using Pro/Web.Link in configuring the family of parts or assemblies.

Pro/Web.Link is a set of routines, protocols, and tools that can change and adjust parts and assemblies in Creo or Pro/Engineer CAD/CAM systems. An embedded web browser in the Creo CAD/CAM system 
improves communication with parts and assemblies in Creo, allowing researchers to concentrate on the process of configuring a new product based on available modules. Pro/Web.Link allows users to rapidly obtain CAD models of components.

The application of Pro/Web.Link provides direct access to information about the model. Moreover, the designer can create, modify, or delete any information regarding the model.

Traditionally, machines have been designed using a classic approach, from smaller to larger (bottomup), i.e., from the components to the main assembly, Fig. 2a. In this case, the necessary information for the main assembly depends significantly on the selected components.

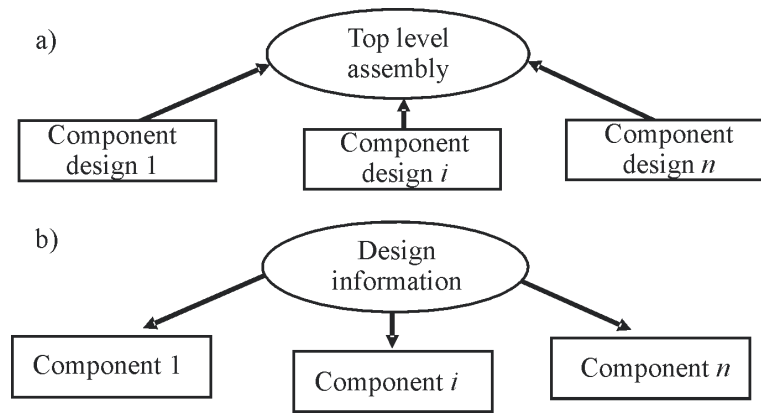

Fig. 2. Different approaches to configuring,

a) bottom-up; b) top-down [26]

Opposite to the bottom-up approach, the topdown approach, [26] and [27], uses system analysis as a method for project management. The structure and basic logic of the top-down approach are shown in Fig. 2b. In this approach, all the data are located at the top level and dictate the essential information needed for components. The result is a component that fits perfectly to the main assembly and requires very little modification later.

The essential features of the top-down approach are: (1) a method for placing critical information at a high-level location, (2) communicating that information to the lower levels of the product structure, and (3) capturing the overall design information at one centralized location [26]. The main goals achieved by the top-down approach are: cycle time reduction, increased user satisfaction with software, design efficiency increase, and cost reduction.

The top-down design strategy is the mostcommon method currently used by industries. This design process is conducted from the system to subsystem, then to the sub-sub-system, and eventually to the part, as shown in Fig. 3. The advantage of the top- down design approach is that inter-linkages from one sub-system to another can be correlated [8].

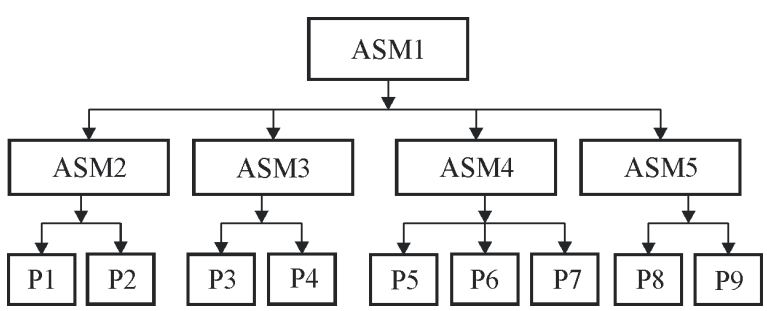

Fig. 3. Top-down design strategy for product development [8]

The main assembly (ASM1) is organized like a tree according to subassemblies (ASM2, ASM3, etc.) and components (P1, P2, P3, etc.), which are allocated to specific project teams and designers who are responsible for their own tasks and who do not and should not view the project as a whole.

The use of a skeleton model is a powerful method for implementing the top-down design. The skeleton model is a simplified assembly, with zero mass and geometry with features such as outer surface contours, parting lines, hole locations, etc. Although it is typically only a non-solid geometry (surfaces, planes, curves, axis, etc.), there is no restriction on what kind of features can be put into a skeleton.

\section{DEVELOPMENT OF THE MINI-LABORATORY AND DESKTOP 3-AXIS PKMM}

Previous experience in the field of PKMM and a successfully developed first experimental prototype of a vertical milling machine based on newly developed parallel mechanism, [19] and [20], inspired the idea of developing a mini-laboratory and desktop 3-axis PKMM.

The structure of the mechanism, modelling approach, inverse and direct kinematics, workspace and singularity analysis of developed mini-laboratory and desktop 3-axis PKMM, as well as control and programming systems have been described in previous research, [16] to [18].

A representation of the initial model of the developed parallel mechanism and analytically obtained workspace are shown in Fig. 4.

The mechanism consists of the moving platform, three joint parallelograms, $c_{1}, c_{2}$, and $c_{3}$, and a stationary base with two parallel guide-ways. Two crossed parallelograms $\left(c_{1}\right.$ and $\left.c_{2}\right)$ with spherical and/ or universal, i.e. cardan joints, are connected with one of their ends to the mobile platform, and with their other ends to the independent sliders $\left(\mathrm{p}_{1}\right.$ and $\left.\mathrm{p}_{2}\right)$ 
which, with a common guideway, make two powered and controlled translatory joints.

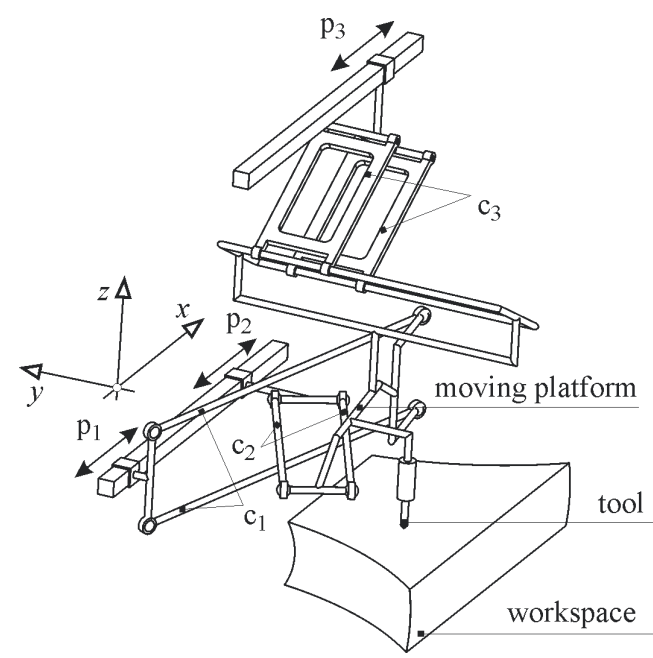

Fig. 4. Parallel mechanism pn101 [13]

The third joint parallelogram $\left(c_{3}\right)$ is connected with one of its ends, through passive translator rotating joints with 2-DOF, to the moving platform. Its other end is connected with rotating joints to the slider $\mathrm{p}_{3}$, which makes, with the second guideway, the third powered and controlled translatory joint. The actuation of sliders $\mathrm{p}_{1}, \mathrm{p}_{2}$, and $\mathrm{p}_{3}$ offers three degrees of freedom to the moving platform, i.e., the tool, so that the platform retains a constant orientation in its motion through the space [16] to [18].

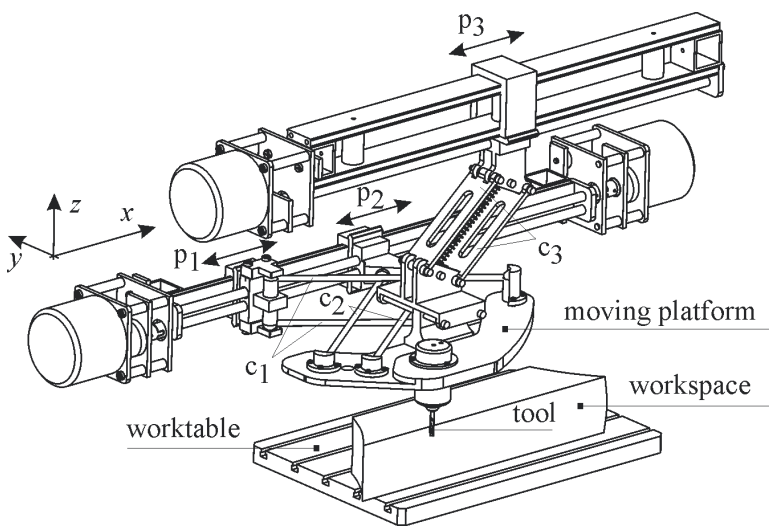

Fig. 5. CAD model of the parallel mechanism pn101_st [17]

Since this machine has guideways in a parallel position, the workspace extension is achieved by elongation of one axis ( $x$-axis).

Configuring the mini-laboratory and desktop 3-axis PKMM is done in the Creo CAD/CAM system, using the top-down approach, PRO/Web.Link and the web CAD configurator for the standard components.
The CAD model of the developed mini-laboratory and desktop 3-axis PKMM are shown in Fig. 5.

\subsection{The Application of Top-Down Approach}

Using the top-down approach, all of the crucial information is at the highest level, from where it is forwarded to the lower levels. During configuring, the skeleton model of a parallel mechanism (Fig. 6) is used to define a plan for integration of parts/ subassemblies in final assembly of the machine (completing the project of machine).

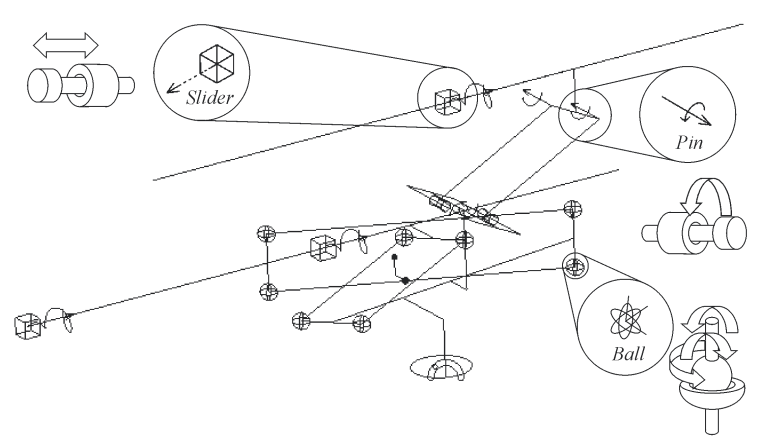

Fig. 6. A simplified assembly of the skeleton model with constraints

This is a critical issue when working with large assemblies. Steps to create the skeleton model of the mechanism for the machine are: (1) the analysis and definition of the machine tool configurations; (2) the definition of assembly interfaces in the assembly model with constraints and parameters; (3) the building of a simplified skeleton model with common geometries and constraint interface of the mechanism for 3-axis PKMM.

The skeleton model (Fig. 6) of the parallel mechanism contains all the crucial parameters of the mechanism and the kinematic relations between moving components. The following kinematic relations are used: (1) a slider joint for moving three sliders $\left(\mathrm{p}_{1}, \mathrm{p}_{2}\right.$, and $\left.\mathrm{p}_{3}\right)$ and the passive translational joint, (2) a spherical joint (ball) for coupling two joint parallelograms $\left(c_{1}\right.$ and $\left.c_{2}\right)$ with the platform and sliders $\left(\mathrm{p}_{1}\right.$ and $\mathrm{p}_{2}$ ) and (3) rotary axes (pins) for the passive rotating joint $\mathrm{c}_{3}$. Illustration of the application of a skeleton model is shown in Fig. 7.

Components and sub-assemblies are integrated into the skeleton model, and, as a result, a parallel mechanism ready for further assembly is obtained. The main machine assembly (ASM0) is organized like a tree, Fig. 8. A large number of standard and 
commercially available components (Igus [4], NSK [5], Bosch [6]) have been used.

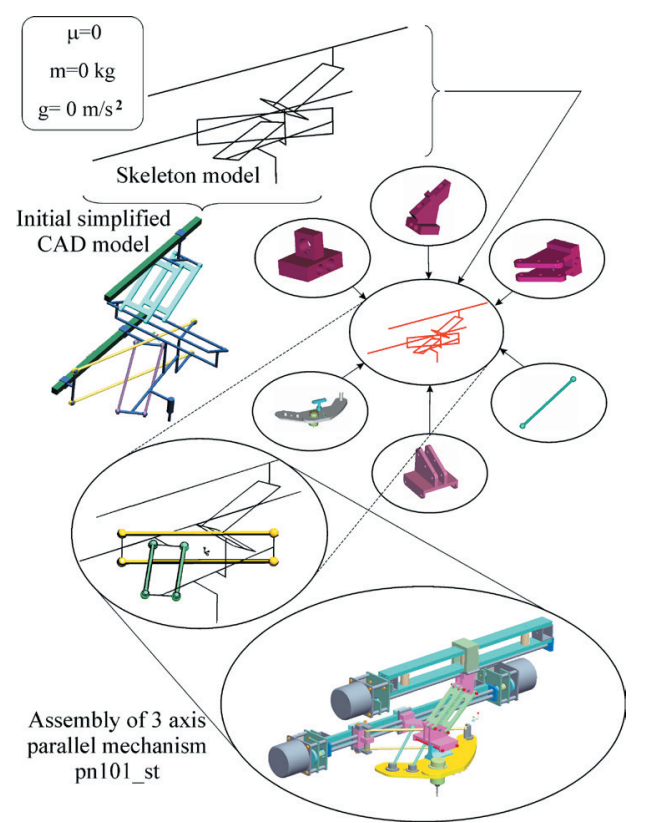

Fig. 7. The application of a skeleton model in configuring

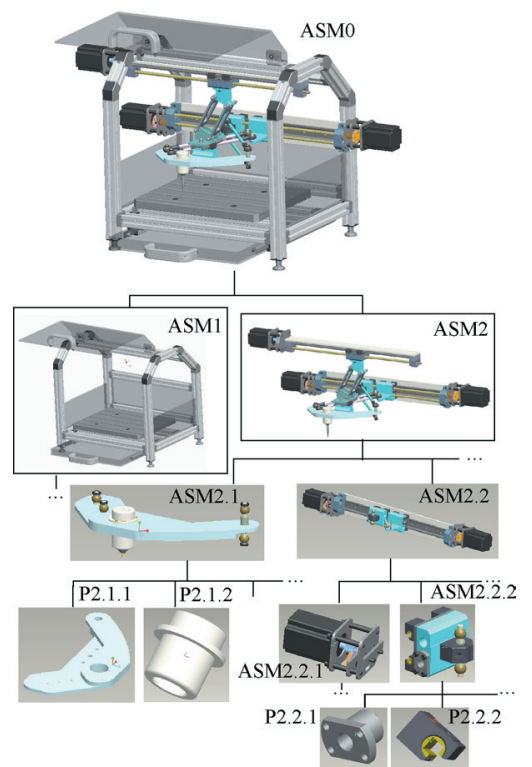

Fig. 8. Design strategy for the development of mini-laboratory and desktop 3-axis PKMM

\subsection{The Application of Pro/WEB.Link}

The dominant axis ( $x$-axis) of the parallel mechanism pn101 can be elongated, which makes the mechanism suitable for the design of a family of machines with different lengths of the $x$ axis. In this section, how the family of supporting structures and guideways can be easily configured using CAD configurator (Pro/WEB. Link) for design of the family of machines is shown.

Fig. 9a presents the web application interface for the CAD configurator for the example of the supporting structure. The configurator for Igus guideways is shown in Fig. 9b. These guideways are used for lead sliders $\left(\mathrm{p}_{1}, \mathrm{p}_{2}\right.$, and $\left.\mathrm{p}_{3}\right)$ and for the passive translatory joint.
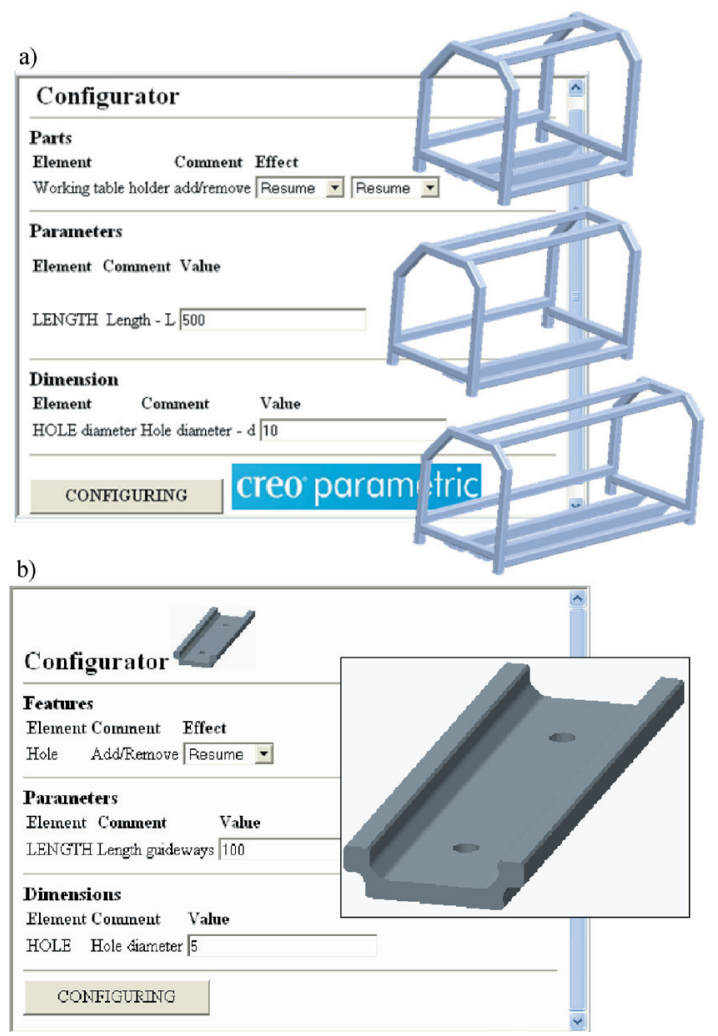

Fig. 9. $C A D$ configurators in Pro/Web.Link a) supporting structure b) Igus guideways

Based on the configurators from Fig. 9, a family of generic modules for configuring the family of machines with different lengths of $x$-axis has been obtained, in which the family parameter is length $(L)$.

\subsection{Virtual Prototypes}

The first low-cost, educational, desktop 3-axis PKMM presented in [16] to [18] was physically realised and was named pn101_st V1. This paper presents a new version (pn101_st V1.5) with small modifications, which includes the protection cover, as well as a trunk for chips, Fig. 10.

This version is configured from available components for realization of the first prototype. Since this is a mini-laboratory and desktop machine, 
its main components (step motors, leadscrews, sliding guideways, joints, etc.) can be easily procured, and all other components can be built in a laboratory.

In addition to the virtual prototype presented in Fig. 10, a virtual prototype of a new version of the machine called pn101_st V2.5, Fig. 11 has been developed and realized. This prototype is configured by using as many standard components as possible, and it is intended for commercial purposes. The pn101_st V1 model is an educational mini-laboratory and desktop 3-axis PKMM whose main components can be purchased commercially; the remaining components can be easily built in the laboratory.

For standard components, some of the common CAD configurators [4] to [6] available on the web have been used; components were downloaded in STEP format, Fig. 1. These components can be easily loaded into any $\mathrm{CAD}$ environment and integrated into the required position in the skeleton model.

Upon analysing virtual prototypes from Figs. 10 and 11, the following details can be observed:

- both prototypes have the same built-in parallel mechanism: pn101;

- the first version (V1.5) is configured, so that it can be made of currently available components with a minimum investment, in order to obtain the first prototype;

- the second version (V2.5) is configured with as many standard components as possible, in order to obtain a virtual prototype of a machine that could be easily homemade; the original idea was to use the machine for educational purposes;

- spherical joints in the first prototype are homemade, while in the second standard Igus spherical joints have been used [4];

- guideways of the passive translatory joint are cylindrical in the first prototype, while they are standard square Igus guideways [4] in the second prototype;

- the supporting structure of the first prototype is made of welded steel profiles, while in the second prototype it is made of standard Bosch Rexroth aluminium profiles and connecting elements [6];

- leadscrews in the first prototype are with a common metrical thread, while in the second prototype ball screws were used;

- in both versions, protecting the workspace with transparent Plexiglas on three sides is planned; the front doors are also transparent, and adapted to the form of the supporting structure. Below the machine is a container for the gathering and disposal of chips.

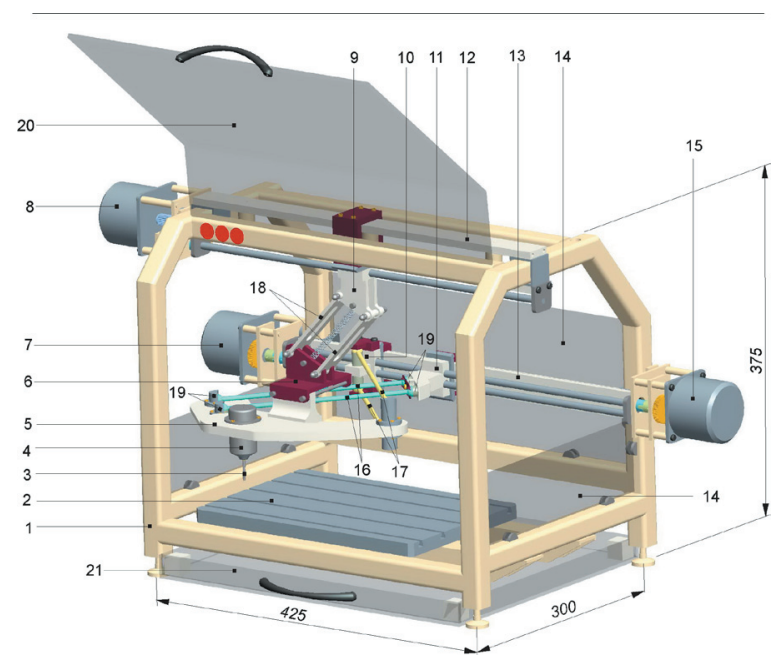

Legend: 1- supporting structure, 2-working table, 3-tool, 4-spindle, 5-moving platform, 6- passive translatory-rotating joints, 7-stepper motor axis $\mathrm{p} 1$, 8- stepper motor axis p3, 9-slider p3, 10-slider p1, 11-slider p2, 12guideways $p 3,13$ - guideways $p 1$ and $p 2,14$ - safety cover, 15-stepper motor axis $p 2,16$ - joint parallelograms $c 2,17$ - joint parallelograms $c 1$, 18- joint parallelograms c3, 19-ball joints, 20- protection cover, 21- container for chip

Fig. 10. CAD model of mini-laboratory and desktop 3-axis PKMM - pn101_st V1.5

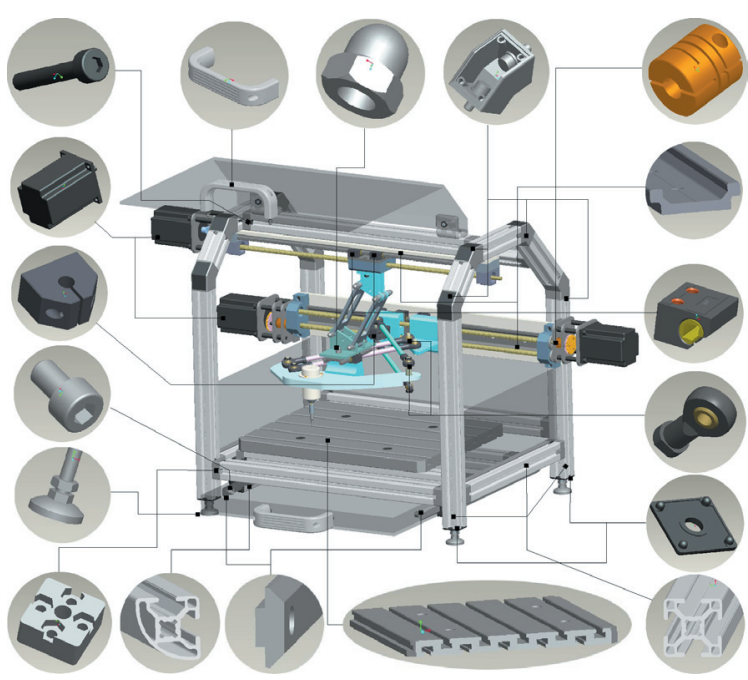

Fig. 11. Mini-laboratory and desktop 3-axis PKMM - pn101_st V2.5

Both virtual prototypes have the same parallel mechanism with identical primary parameters designed with different components. The first prototype (pn101_st V1.5) is designed to use available components, while the second prototype (pn101_st V2.5) is designed to use standard components. The second prototype is planned for further commercial development. 


\section{MACHINING SIMULATION IN THE CAD/CAM SYSTEM}

The configured virtual prototypes are used for the verification of the programming system in a CAD/ CAM environment by machining simulation based on the generated tool path, which also includes machine simulation. This machining simulation is critical in order to: (i) configure the off-line programming environment, (ii) verify the program before machining, (iii) detect the collision of the parallel mechanism during program execution, and (iv) verify the position of the workpiece within the workspace of a parallel mechanism.

Machining simulation by running the program is possible thanks to the applied modelling of the parallel mechanism with all kinematic connections between the components, which allows the motion of a virtual model as a system of rigid bodies.

Fig. 12 shows a detailed virtual prototype of parallel mechanism with all kinematic relationships defined in the same way as shown in the skeleton model in Fig. 6.

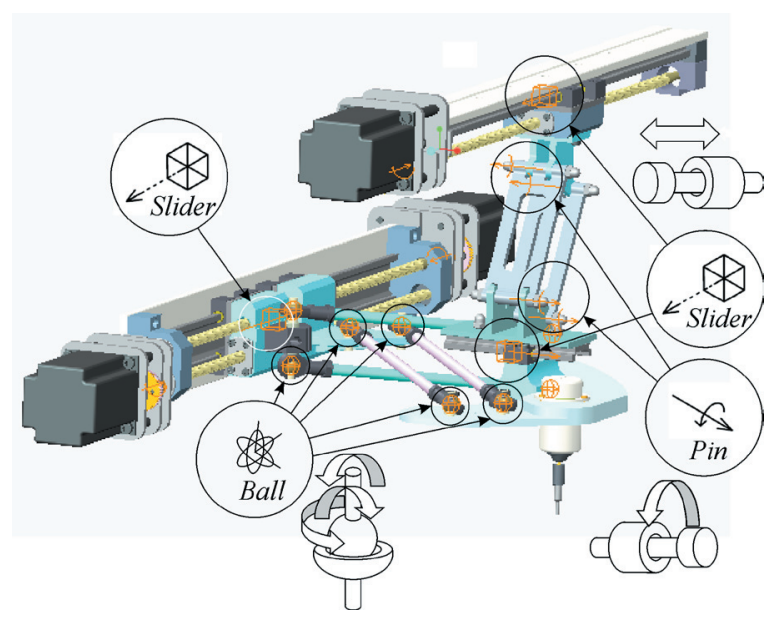

Fig. 12. CAD model for the simulation of mechanism kinematics

This assembly enables the motion of models in the range defined for each connection, which is of particular importance for the identification of possible collisions during the work of the parallel mechanism.

Machining simulation of the virtual prototype allows the motion of movable segments with a tool at the end. The tool path is a result of the execution program obtained by programming using the $\mathrm{CAD} /$ CAM system. The machine is programmed in the programming format based on the $\mathrm{G}$ code.

Although this is a parallel kinematic machine, the same resources are used for its programming as for the machine tool with serial kinematics. Post-processing is done as for a 3-axis vertical milling machine. The postprocessor is configured using the postprocessor generator in the Creo $\mathrm{CAD} / \mathrm{CAM}$ system. The equations of direct and inverse kinematics are incorporated into the control system for this machine [16] and [17].

For the first test, a scaled ISO test workpiece whose dimensions are $50 \times 50 \times 12.5 \mathrm{~mm}$ is used. Because of the particular shape and size of the workspace of parallel kinematics machines, attention should be paid when setting up a workpiece, which must be within the limits of the workspace of the machine. For the test workpiece shown in Fig. 13a, the zero point in the middle of the underside of the workpiece has been adopted, with the coordinate axes $x, y, z$ as has been used in the vertical 3-axis milling machine, marked as MACH_ZERO. The identical zero point (MACH_ZERO) exists on the machine (on the working table) on which the workpiece is placed, Fig. 13c. Matching these two coordinate systems is accomplished by setting the workpiece on the machine during the machining simulation. Fig. 13b presents the simulated tool path on the scaled ISO test workpiece, based on the generated CL file. The tool coordinate system is defined in the same way as the workpiece coordinate system and marked as a TOOL_POINT (Figs. 13b and d).

During the simulation of tool paths, a complete prototype of the virtual machine can be included into the simulation, with a machine play option. An example of machine simulation for virtual prototype pn101_st V2.5 is shown in Fig. 14 for an ISO test workpiece.

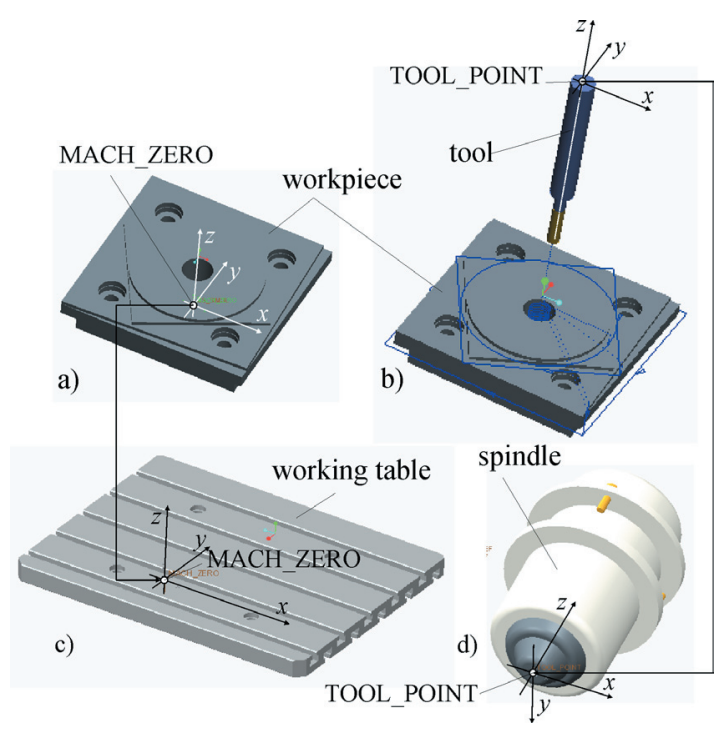

Fig. 13. Coordinate system of the workpiece and tool with tool path simulation 


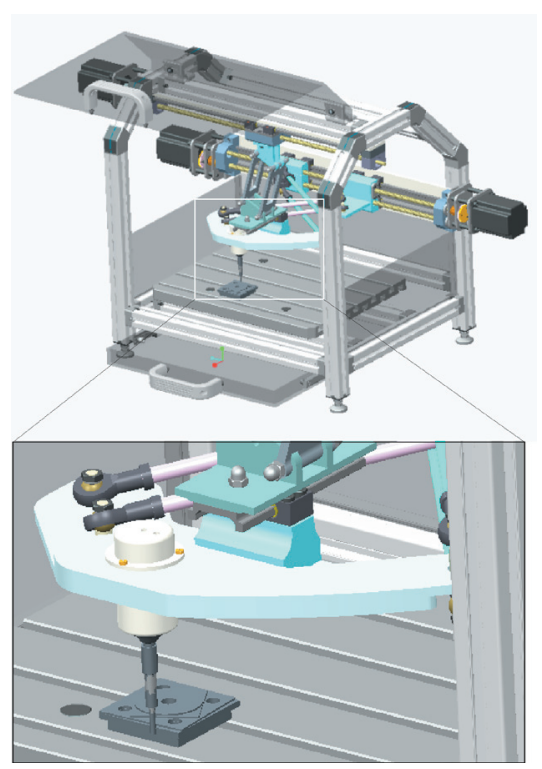

Fig. 14. Machining simulation in the $C A D / C A M$ system - pn101_st V2.5

Fig. 15 presents the second test with a machining simulation of the virtual prototype of real world machine pn101_st V1.5. For the machining test and verifying control and programming system, a nonstandard test workpiece with a grid of slots was chosen [28].

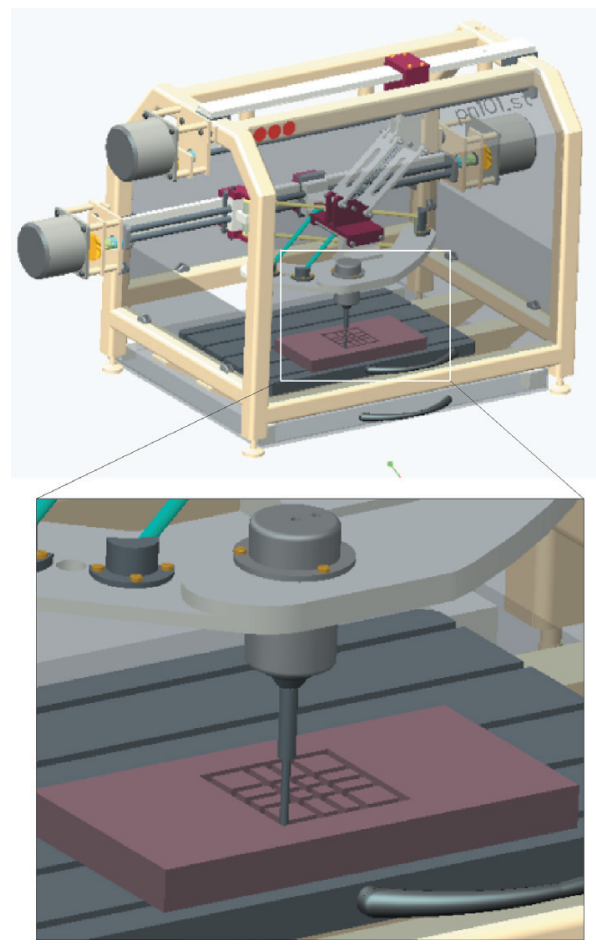

Fig. 15. Machining simulation in the CAD/CAM system - pn101_st V1.5
This type of workpiece is used since linear interpolation represents a significant test for the parallel kinematic machine. A linear motion is perhaps one of the most difficult motions that parallel kinematic machines can perform.

Based on the realized simulations of machine virtual prototypes according to the running programs, no collision between the machine elements was observed during program execution. Accordingly, we can state that these tests have successfully verified the programming system and program in $\mathrm{G}$ code for both machine virtual prototypes. For the prepared program, the workpiece is set in workspace boundaries correctly and workpiece machining can be performed without collision.

\section{MACHINING TEST}

The model pn101_st V1.5 mini-laboratory and desktop 3-axis PKMM has been built and tested in our laboratory. While it is educational system with complex kinematics, a virtual machine is included in the control and programming system too [17]. A virtual machine configured in the Python object-oriented programming language is implemented in the control system's enhanced machine controller (EMC2) in an axis graphical users interface (GUI) [29], for program simulation and verification, Fig. 16.

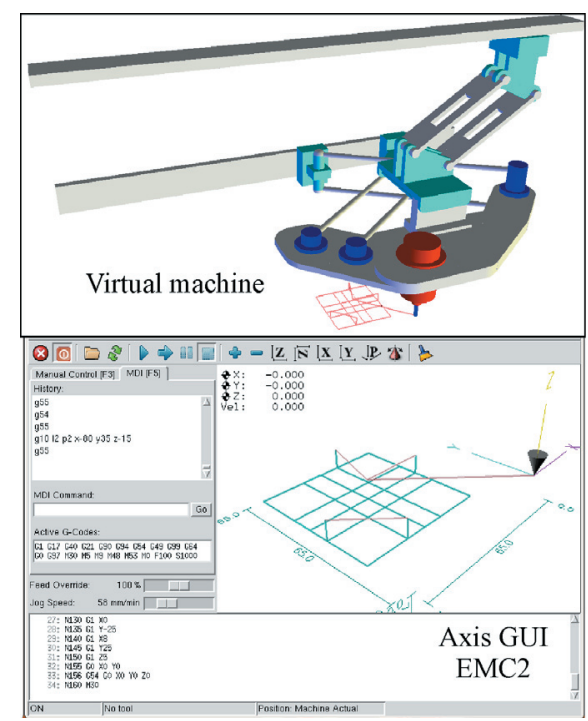

Fig. 16. Virtual machine - pn101_st V1.5 for program simulation and verification

A completely realized version of the machine (pn101_V1.5) during a real world machine verification is shown in Fig. 17a. Both test workpieces considered in the machining simulation were used for 
verifying control and programming the system. The machined ISO test workpiece is shown in Fig. 17b, and a machined non-standard test workpiece with grid of slots is shown in Fig. 17c.

Dimensions of the workpieces are set according to the dimensions of the machine workspace. These two test workpieces (Figs. 17b and c) were made of Styrofoam. In both cases, a flat end mill tool (diameter $3 \mathrm{~mm}$ ) was used. These experiments confirmed that it is possible to realize a low-cost mini-laboratory and desktop 3-axis PKMM for workpieces of light materials and lower tolerances, which can be directly used by students, $\mathrm{CNC}$ machine tool programmers and operators.

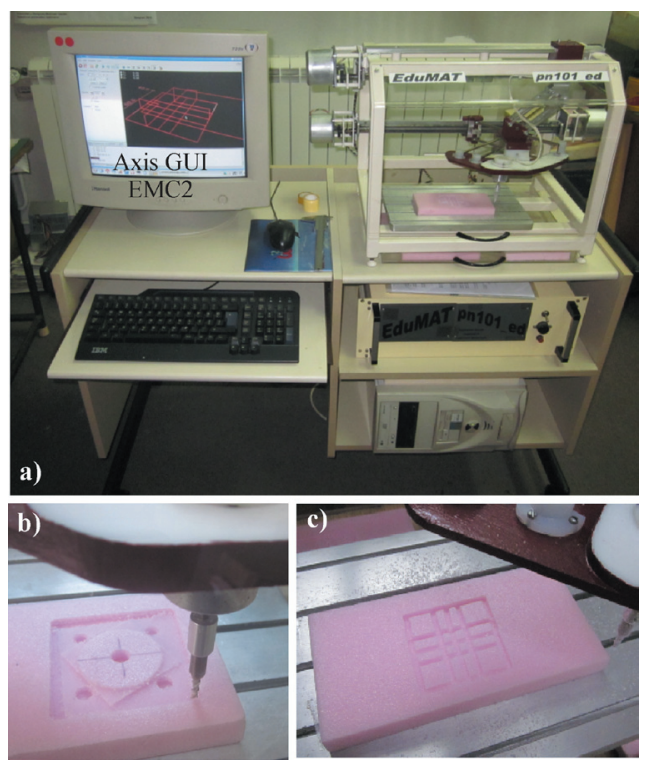

Fig. 17. Machining tests

For this machine, in the future we are planning to upgrade the control system, so that it can be utilized for research and application of the new method of programming known as STEP-NC [30]. Furthermore, we will consider the upgrade of the existing parallel mechanism by adding a two-axis serial head on the platform, so that the machine tool can be used for five-axis machining.

\section{CONCLUSIONS}

In order to contribute towards the acquisition of practical experiences in configuring, design, control, programming, verification and the use of a PKMM, we have developed a mini-laboratory and desktop 3-axis parallel kinematic milling machine.

Two versions of mini-laboratory and desktop 3-axis PKMM have been considered. The first version of the machine was completely carried out, while the second represents a project for possible commercial development for education. Both machines use the same parallel mechanism, which is incorporated into the skeleton model. The difference in machine design is in the components that are built in the skeleton model using specially developed and standard CAD configurators. In its essence, this is a top-down approach, since we start from the basic idea represented by the machine skeleton, which is further developed depending on the available components and desired machine parameters.

The concept of the mini-laboratory and desktop 3 -axis PKMM was verified by simulation and by the machining of standardized test pieces. The simulation enabled prior identification of possible collisions between the machine elements during program execution and verification, regardless of whether the parallel mechanism motion is within the boundaries of the machine workspace.

The developed mini-laboratory and desktop 3-axis PKMM represents a comprehensive and sophisticated didactic facility. It can machine soft materials, it is programmable in a conventional way, and it is completely safe for beginners to use.

\section{ACKNOWLEDGEMENT}

The author would like to thank the Ministry of Education, Science and Technological Development of Serbia for providing financial support that made this work possible.

\section{REFERENCES}

[1] Chen, S., Wang, Y., Tseng, M. (2009). Mass customisation as a collaborative engineering effort, International Journal of Collaborative Engineering, vol. 1, no. 1/2, p. 152-167, DOI:10.1504/IJCE.2009.027444.

[2] McCarthy, I.P. (2004). Special issue editorial: the what, why and how of mass customization. Production Planning \& Control, vol. 15, no. 4, p. 347-351, DOl:10.1080/0953728042000238854.

[3] Simpson, T.W. (2004). Product platform design and customization: Status and promise. Artificial Intelligence for Engineering Design, Analysis and Manufacturing, vol. 18, no. 1, p. 3-20, DOI:10.1017/\$0890060404040028.

[4] Igus CAD Configuration (2013), from http://igus.kimweb.de/ index.asp, accessed on 2013-10-17.

[5] NSK Precision America, Solid Components (2013), from http://www.solidcomponents.com/company/default.asp, accessed on 2013-10-22.

[6] Bosch Rexroth Corp., CAD Files and Solid Models (2013), from http://boschrexroth.com, accessed on 2013-10-27. 
[7] Lewis, C. (2004). Pro/Web.Link Trailer Configurator Demo, Picks \& Script - Setup \& Reset. Technical Demonstration Development. Parametric Technology Corporation.

[8] Wang. C.S. (2009). Web-based modular interface geometries with constraints in assembly models. Computers \& Industrial Engineering, vol. 56, no. 4, p. 1675-1686, D0l:10.1016/j. cie.2008.10.018.

[9] Deciu, E.R., Ostrosi, E., Ferney, M., Gheorghe, M. (2008). Product family modelling in conceptual design based on parallel configuration grammars. Strojniški vestnik - Journal of Mechanical Engineering, vol. 54, no. 6, p. 398-412.

[10] Jiao, J., Simpson, T., Siddique, Z. (2007). Product family design and platform-based product development: a state-of-the-art review. Journal of Intelligent Manufacturing, vol. 18, no. 1, p. 5-29, D0I:10.1007/s10845-007-0003-2.

[11] Simpson, T.W., Maier, J.R.A., Mistree, F. (2001). Product platform design: Method and application. Research in Engineering Design, vol. 13, no. 1, p. 2-22, D0l:10.1007/ s001630100002.

[12] Du, X., Jiao, J., Tseng, M.M. (2001). Architecture of product family: Fundamentals and methodology. Concurrent Engineering: Research and Application, vol. 9, no. 4, p. 309325, D0I:10.1177/1063293X0100900407.

[13] Zivanovic, S. (2012). Development of Educational Parallel Kinematic Machine. Zaduzbina Andrejevic, Beograd. (in Serbian)

[14] Weck, M., Staimer, D. (2002). Parallel kinematic machine tools-current state and future potentials. CIRP Annals Manufacturing Technology, vol. 51, no. 2, p. 671-683, DOI:10.1016/S0007-8506(07)61706-5.

[15] Cheng, G., Xu, P., Yang, D., Li, H., Liu, H. (2013). Analysing kinematics of a novel 3CPS parallel manipulatorm based on rodrigues parameters. Strojniški vestnik - Journal of Mechanical Engineering, vol. 59, no. 5, p. 291-300, DOl:10.5545/sv-jme.2012.727.

[16] Milutinovic, D., Glavonjic, M., Zivanovic, S., Dimic, Z., Kvrgic, V. (2008). Mini educational 3-axis parallel kinematic milling

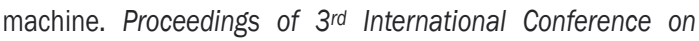
Manufacturing Engineering ICMEN and EUREKA Brokerage Event, Kallithea of Chalkidiki, p. 463-474.

[17] Glavonjic, M., Milutinovic, D., Zivanovic, S., Dimic, Z., Kvrgic, V. (2010). Desktop 3-axis parallel kinematic milling machine. The International Journal of Advanced Manufacturing Technology, vol. 46, no. 1-4, p. 51-60, D0l:10.1007/s00170-009-2070-3.
[18] Zivanović, S., Glavonjić, M., Dimić, Z. (2009). Methodology for configuring desktop 3-axis parallel kinematic machine. FME Transactions, vol. 37, no. 3, p. 107-115.

[19] Milutinovic, D., Glavonjic, M., Kvrgic, V., Zivanovic, S. (2005). A new 3-DOF spatial parallel mechanism for milling machines with long $X$ travel. Annals of the CIRP, vol. 54 , no. 1 , p. 345348, D0I:10.1016/S0007-8506(07)60119-X.

[20] Glavonjic, M, Milutinovic, D. (2008). Parallel structured milling machines with long $X$ travel. Robotics and Computer-Integrated Manufacturing, vol. 24, no. 3, p. 310-320, D0l:10.1016/j. rcim.2006.12.001.

[21] Vijay Sekar, K.S., Pradeep Kumar, M. (2012). Optimising flow stress input for machining simulations using taguchi methodology. International Journal of Simulation Modelling, vol. 11, no. 1, p. 17-28, Dol:10.2507/IJSIMM11(1)2.195.

[22] Deng, W.J., Xie, Z.C., Li, Q., Lin, P. (2013). Finite element modelling and simulation of chip breaking with grooved tool. International Journal of Simulation Modelling, vol. 12, no. 4, p. 264-275, DOI:10.2507/IJSIMM12(4)5.250.

[23] Kopač, J., Kržič, P. (2008). CAM algorithm as important element by achieving of good machined surface quality. Strojniški vestnik - Journal of Mechanical Engineering, vol. 54, no. 4, p. 280-287.

[24] Lewis, C. (2008). A Pro/Engineers Guide to Pro/Web.Link, Printed on-demand by, www.lulu.com.

[25] Creo Parametric 1.0. (2011). Pro/Web.LinkUser's Guide, Parametric Technology Corporation, 140 Kendrick Street, Needham.

[26] Remmers, V. (2006). Top-down design tools-managing complex assemblies, tips \& techniques. Parametric Technology Corporation, The way to product first, from $h t t p: / /$ www.ptcuser.nl/conf_06/presentations/T\%20\&\%20T\%20 Top-Down\%20Design.ppt, accessed on 2013-10-30.

[27] Pro/Engineer: Top-down Design Task Guide: Release 20.0. (1998). Parametric Technology Corporation.

[28] Powel, N.P., Whittingham, B.D., Gindy, N.N.Z. (1999). Parallel Link Mechanism Machine Tools: Acceptance Testing and Performance Analysis, Parallel Kinematic Machines Theoretical Aspects and Industrial Requirements, SpringerVerlag, London.

[29] Linux CNC: Software for real-time control (2013). from http:// www.linuxcnc.org, accessed on 2013-04-30.

[30] Kržič, P., Stoic, A., Kopač, J. (2009). STEP-NC: A New Programming Code for the CNC Machines. Strojniški vestnik Journal of Mechanical Engineering, vol. 55, no. 6, p. 406-417. 